


About IJMA
International Journal of Medical Arts is the Official Scientific Journal
of the Damietta Faculty of Medicine, Al-Azhar University, Egypt
It is an International, Open Access, Double-blind, Peer-reviewed,
monthly-published (starting January 2022) Journal
The First Issue was published in July 2019
Published under the following license: Creative Commons
Attribution-ShareAlike 4.0 International Public License (CC BY-SA
4.0).
The Egyptian Knowledge Bank hosts the web site and supports
IJMA follows the regulations of the International Committee of
Medical Journal Editors
IJMA is a member of the International Society of Managing and
Technical Editors
IJMA is indexed in the "Directory of Open Access Journals"
[Indexed on 15 January 2021], Index Copernicus and J-Gate [29-6-
IJM21].
IJMA Listed in
"Publons", "Academic resource index [ResearchBib]", "Electronics journal
Jibrary", "Eurasian Scientific Journal Index", World Catalogue of Scientific
WorldCat and "Citefactor"




Available online at Journal Website
https://ijma.journals.ekb.eg/
Main Subject [Surgery]

Original Article

\title{
Role of Vacuum-Assisted Closure Therapy in the Management of Exposed Mesh after Ventral Hernia Repair
}

\author{
Mahmoud Elsayed Nagaty \\ Department of General Surgery, Faculty of Medicine, Al-Azhar University, Cairo, Egypt
}

\begin{tabular}{|c|}
\hline Article information \\
\hline \begin{tabular}{l||l} 
Submitted: & $02-12-2021$
\end{tabular} \\
\hline \begin{tabular}{l||l} 
Accepted: & $05-01-2022$
\end{tabular} \\
\hline DOI: 10.21608/IJMA.2022.109196.1403 \\
\hline $\begin{array}{l}\text { *Corresponding author } \\
\quad \text { Email: dr_nagaty84@yahoo.com }\end{array}$ \\
\hline $\begin{array}{l}\text { Citation: Nagaty ME. Role of Vacuum- } \\
\text { Assisted Closure Therapy in the } \\
\text { Management of Exposed Mesh after } \\
\text { Ventral Hernia Repair. IJMA 2022 Jan; } 4 \\
\text { [1]: } 2082-2087 \\
\text { 10.21608/JMA.2022.109196. 1403]. } \\
\text { [DOI: }\end{array}$ \\
\hline
\end{tabular}

\section{ABSTRACT}

Background: Mesh-related infection after open ventral hernia repair is a clinical dilemma in abdominal wall hernia surgery, especially in the bacterial resistance era. The management of such a problem usually needs complete mesh excision, which results in a high recurrence rate.

Objective: The goals of the current study were to evaluate the efficacy of negative pressure wound therapy [NPWT] in infected mesh preservation.

Patients and Methods: This prospective study was carried out from January 2017 to December 2019. A total of twenty-four cases with mesh exposure after ventral hernia repair was involved in our study. Patients were categorized into two comparable groups, Group I: VAC was applied for the preservation of the infected mesh, Group II: conventional wound care dressing was used. Patients' demographics, types of hernia, wound diameter, and the outcomes of each technique were recorded in the study.

Results: Out of 24 patients there were 9 males and 15 females, the mean age was 42 years. Types of hernias were 15 paraumbilical hernias, 6 incisional hernias, and 3 recurrent hernias. The wound size in group I ranged from $18 \times 11 \mathrm{~cm}-8.5 \times 5 \mathrm{~cm}$ and in group II ranged from $16.5 \times 10 \mathrm{~cm}-7 \times 5$. In Group I, the mesh salvage was accomplished in 11 cases [91.7\%] and the wound closed with 2ndary suturing and only 1 [8.3\%] patient need partial mesh excision. While In Group II, mesh salvage was accomplished in 5 cases [41.7\%] however, 7 [58.3\%] patients needed radical en-bloc mesh excision. All the cases had followed up for 6 months.

Conclusion: NPWT/VAC therapy has excellent and promising outcomes in the preservation of infected prosthesis.

Keywords: Ventral hernia repair; Infected mesh; Vacuum-assisted closure.

This is an open-access article registered under the Creative Commons, ShareAlike 4.0 International license [CC BY-SA 4.0] [https://creativecommons.org/licenses/by-sa/4.0/legalcode.

\section{INTRODUCTION}

Ventral hernia repair by using synthetic mesh is considered the gold standard strategy in treatment. Using prosthetic mesh in hernia repair markedly decreases hernia recurrence by about $30 \%{ }^{[1]}$. However, the main drawback of using prosthetic mesh is liable to infection. The mesh infection is defined as the existence of suppuration, or purulent exudate over the mesh. A superficial infection is an infection that involves the superficial layers such as skin and subcutaneous tissue, while a deep infection is an infection that involves deeper layers such as the fascia, and the muscle ${ }^{[2]}$. The mesh infection incidence rate after hernia repair ranges from $1 \%$ to $7-8 \%{ }^{[3-5]}$. It is very difficult to find the precise ratio due to the major variability in clinical presentation and onset, which may start immediately or a long time after surgery. The mesh-related infection causes great suffering to the patient due to more hospitalization period, additional financial burden, and psychological consequences. The treatment strategy of the infected prosthesis includes early en-block excision of the mesh and optimum wound care ${ }^{[3-7]}$. However, mesh removal may accompany 
by undesired consequences such as dehiscence of the abdominal wall, and hernia recurrence. NPWT/VAC is a recent technique in the management of gapped wounds and meshrelated infections. This modality accelerates the healing process by expelling excess fluid exudates, improving blood supply, and promoting neovascularization together with the formation of granulation tissue. In addition, it promotes shrinking of the defect edges and decreases wound size ${ }^{[8-10]}$.

\section{THE AIM OF THE WORK}

The present study aimed to weigh the utility of NPWT in the preservation of infected mesh following ventral hernia repair and the patientrelated outcomes.

\section{METHODS}

The present study was achieved from January 2017 to December 2019. A total of twenty-four patients suffering from infected wound and mesh exposure after various types of ventral hernia repair participated in our study. Patients were randomly categorized into two comparable groups, Group I: VAC was applied for the preservation of the infected mesh, Group II: conventional wound care dressing was used for the same purpose. All patients provided written consent to participate in this study.

Inclusion criteria: Patients with infected wound and mesh exposure after open hernia repair [incisional, paraumbilical, and recurrent].

Exclusion criteria: Minor superficial infections were excluded. Patients with infected mesh after inguinofemoral hernia repair.

\section{Procedures}

In Group I: VAC was applied for the preservation of the infected/exposed mesh. VAC therapy procedure involved a planned usage of negative pressure to the wound defect with the aid of a sealed wound dressing, which was connected to a suction device. Initially, we measured the wound diameter and good surgical debridement of all the necrotic tissue was done under anesthesia. After that, the wound diameter was measured again, and VAC was utilized. A specific sponge was trimmed and designed depending on the defect size, shape, and depth. A catheter with numerous openings at the tip was applied inside the sponge maintaining all openings remained inside the sponge. After that, the sponge was fitted inside the defect just above the infected mesh. Transparent airtight dressings [opposite sheets] were inserted over the defect and sponge then the end of the tube was brought out through the dressing [Figure 1]. The other end of the tube was then attached to a suction device for applying negative pressure.

Negative pressure was adjusted to minus 100 to minus $120 \mathrm{~mm} \mathrm{Hg}$ during the period of VAC therapy and the apparatus was adjusted to ten-minute intervals. During the first two sessions of therapy, we changed the wound dressing every 3 days, after that the dressing was replaced every 5 - 7 days according to the status of wound cleanliness and healing. NPWT/VAC sessions were continued until the mesh was entirely covered by healthy granulation and wound diameter decreased to an acceptable size [Figure 2a].

Antimicrobials were used according to the guide of culture and sensitivity results. When the mesh was entirely covered with healthy tissue, the defect was cleaned with $0.9 \%$ normal saline and closed either by 2ndary sutures or grafting based on the diameter of the defect [Figure 2b]. A follow-up was completed to 6 months after healing to detect hernia recurrence or other wound complications.

In Group II: Good wound debridement, pus drainage, then wound lavage with $0.9 \%$ saline/Povidone Iodine was done. These measures were repeated until the wound and mesh were clear of pus and necrotic tissue. Purulent discharge was taken for culture and sensitivity. Daily wound care was repeated until the wound was clean and the prosthesis completely covered by healthy tissue then closure of the wound was done. In cases that failed to completely cover the mesh with granulation tissue, radical en-bloc excision of the prosthesis was done. 


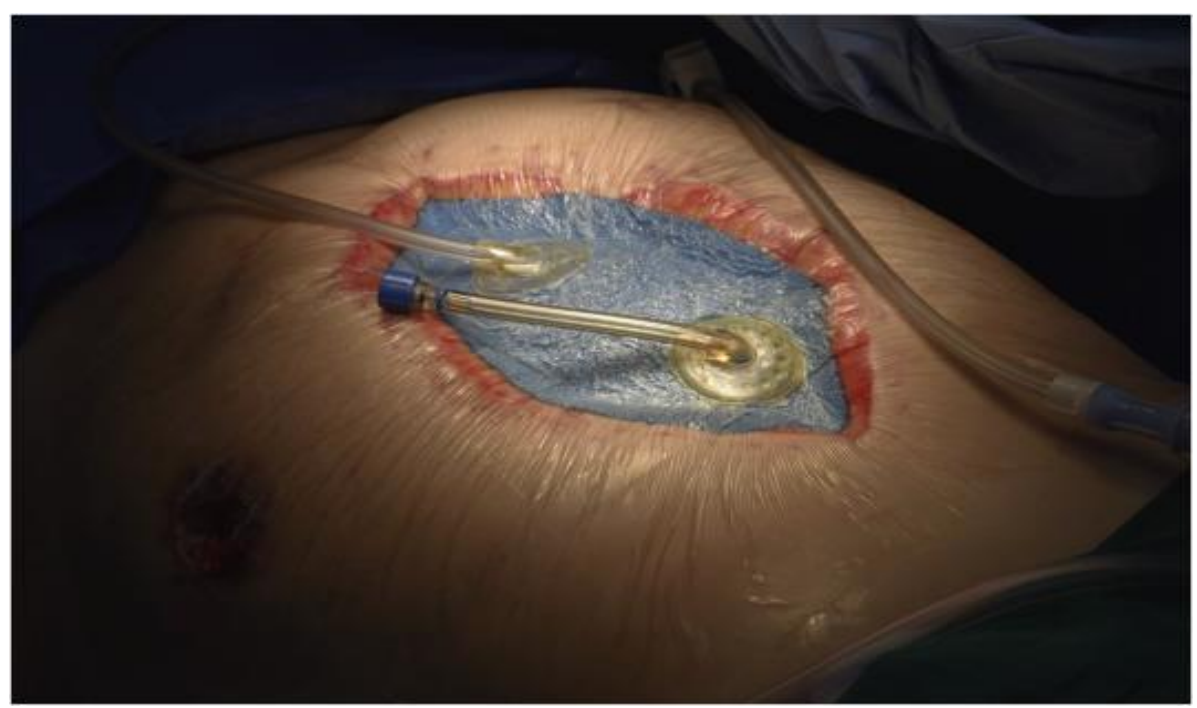

Figure [1]: VAC dressing- black sponge was fitted in the defect with sealing dressing
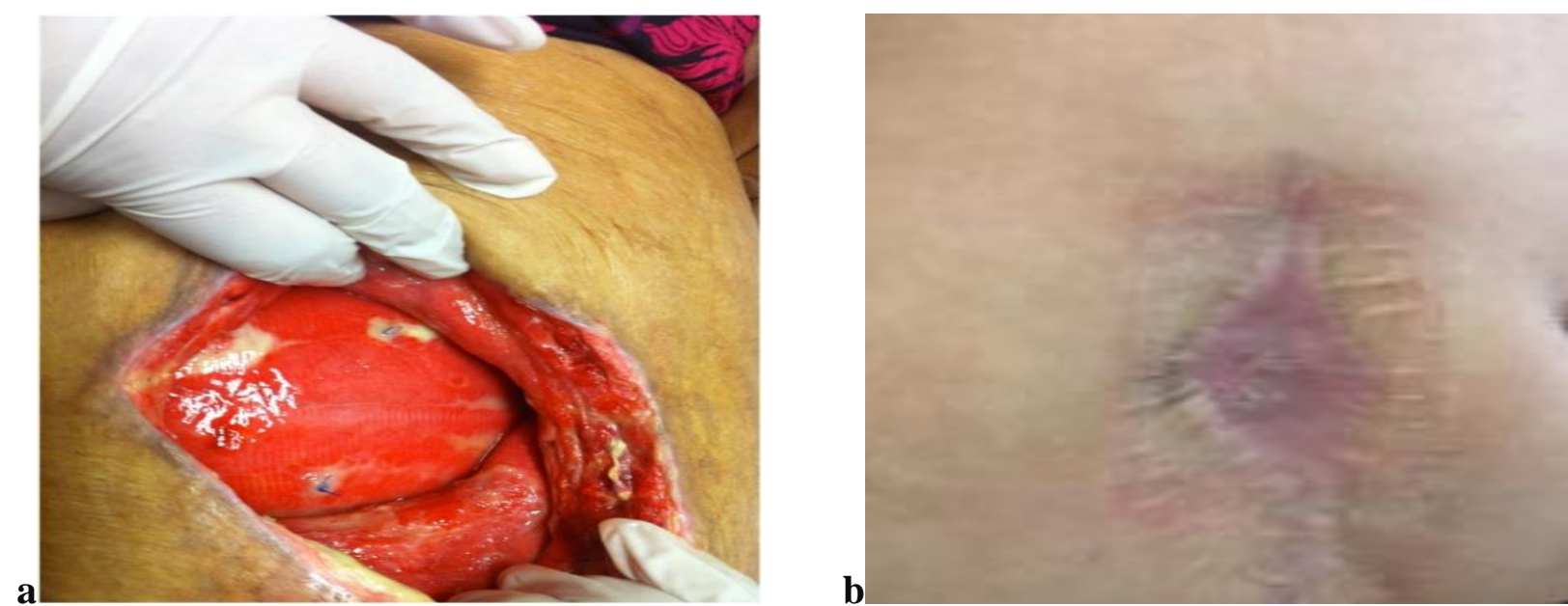

Figure [2]: a, the mesh is completely covered with granulation tissue. B: Wound healing by 2ndary intention.

Statistical management: Quantitative data were presented as mean + standard deviation [SD] and qualitative data were presented as numbers and percentages.

Ethical considerations: This study was approved by the Ethics Board of Al-Azhar University and an informed written consent was taken from each participant in the study. The study has been performed according with The Code of Ethics of the World Medical Association [Declaration of Helsinki] for studies involving humans.

\section{RESULTS}

A total of 24 cases participated in this study, $62.5 \%$ [15] were females and $37.5 \%$ [9] were males. The mean age of all participants was $41.85 \pm 6.84$ years and the mean body mass index was $36.02 \pm 4.97 \mathrm{~kg} / \mathrm{m}^{2}$. Types of hernias are shown in table [1].

Table [2] describes the co-morbidities of the study patients. 21 patients were diabetic, 13 patients were hypertensive. Chronic kidney disease, and steroid therapy were present in $12.5 \%$ and $4.2 \%$ of the study patients respectively. Out 24 cases, 8 had multiple or more than one comorbidity.

Table [3] shows the type of isolated bacteria from the 24 cases after debridement. Pseudomonas was present in $20.8 \%$ of cases, other bacteria like Escherichia coli [E. coli] in $16.7 \%$, Staphylococcus aureus in $8.3 \%$, Streptococcus sp. in $12.5 \%$, and MRSA in $4.2 \%$. Out of 24 patients, 9 had mixed infection with more than one organism. 
Table [4] shows the wound diameter for each patient before the application of VAC or traditional dressing. Wound diameter was evaluated after debridement and after 3 weeks. There were a 57\%-63\% reduction in defect diameter after 3 weeks in group I and only $28 \%-32 \%$ in group II. The study showed significant difference between the two groups with p-value $<0.001$.

Out of the 12 cases in group I, the mesh was salvaged and infection was eliminated in 11
[91.7\%], and only one [8.3\%] patient needed partial mesh excision. While In Group II, the mesh salvage was accomplished in 5 cases [41.7\%] and 7 [58.3\%] patients needed an excision of the mesh. All the cases had followed up for 6 months. Two cases had recurrence after complete mesh excision. The study showed significant difference between the two groups with p-value $<0.001$ [Table 5] shows the outcomes regarding mesh salvage and recurrence after mesh excision.

Table [1]: Various types of hernia in the study

\begin{tabular}{|l|c|c|c|c|}
\hline Types of hernia & \multicolumn{2}{|c|}{ Group I } & \multicolumn{2}{c|}{ Group II } \\
\hline Paraumbilical hernia & Number & $\%$ & Number & $\%$ \\
\hline Incisional hernia & 7 & $58.3 \%$ & 8 & $66.7 \%$ \\
Recurrent hernia & 3 & $25 \%$ & 3 & $25 \%$ \\
\hline
\end{tabular}

Table [2]: Co-morbidities of the study patients

\begin{tabular}{|l|c|c|}
\multicolumn{1}{|c|}{ Co-morbidity } & Number & $\%$ \\
\hline Diabetes mellitus & 21 & $87.5 \%$ \\
\hline Hypertension & 13 & $54.2 \%$ \\
\hline Chronic kidney disease & 3 & $12.5 \%$ \\
\hline Steroid therapy & 1 & $4.2 \%$ \\
\hline
\end{tabular}

Table [3]: Types of isolated organisms from the wound samples

\begin{tabular}{|l|c|c|}
\hline \multicolumn{1}{|c|}{ Organisms isolated } & Total number & Percentage \\
\hline Pseudomonas sp. & 5 & 20.8 \\
\hline Escherichia coli & 4 & 16.7 \\
\hline Staphylococcus aureus & 2 & 8.3 \\
\hline Streptococcus sp. & 3 & 12.5 \\
\hline Methicillin-resistant Staphylococcus aureus [MRSA] & 1 & 4.2 \\
\hline Mixed infections & 9 & 37.5 \\
\hline
\end{tabular}

Table [4]: Wound size at the start and after 3 weeks

\begin{tabular}{|l|c|c|c|c|}
\hline & \multicolumn{3}{|c|}{ Wound size } \\
\hline Case No & $\begin{array}{c}|c| \\
\text { After } \\
\text { debridement }\end{array}$ & After 3 weeks & $\begin{array}{c}\text { After } \\
\text { debridement }\end{array}$ & After 3 weeks \\
\hline 1 & $18 \times 11$ & $7.2 \times 4.5$ & $16.5 \times 10$ & $11.5 \times 7.1$ \\
2 & $17 \times 6$ & $6.8 \times 2.4$ & $7 \times 5.5$ & $5 \times 4$ \\
3 & $14 \times 9$ & $5.6 \times 3.6$ & $15.6 \times 7$ & $11 \times 5$ \\
4 & $17 \times 8$ & $7.3 \times 3.2$ & $13 \times 9.5$ & $9.2 \times 6.6$ \\
5 & $9.8 \times 5$ & $4 \times 2.5$ & $16 \times 7.8$ & $11.2 \times 5.5$ \\
6 & $14 \times 10.5$ & $5.2 \times 4$ & $8.5 \times 6.2$ & $6 \times 3.5$ \\
7 & $15.4 \times 10$ & $6 \times 4$ & $10 \times 7.5$ & $7.2 \times 5.3$ \\
8 & $17 \times 8.6$ & $6.8 \times 3.4$ & $14 \times 9.5$ & $9.8 \times 6.6$ \\
9 & $16 \times 10$ & $6.4 \times 4.2$ & $15.8 \times 11$ & $11 \times 7.7$ \\
10 & $14 \times 9.5$ & $5.5 \times 3.8$ & $14.2 \times 8$ & $10 \times 5.5$ \\
11 & $8.5 \times 5$ & $3.5 \times 2.2$ & $12.5 \times 9.3$ & $8.7 \times 6.5$ \\
12 & $14 \times 10.2$ & $5.7 \times 4.2$ & $13.8 \times 7.7$ & $9.7 \times 5.4$ \\
\hline
\end{tabular}




\begin{tabular}{|l|c|c|c|c|}
\hline \hline \multicolumn{1}{|c|}{ Table [5]: The study outcome } & \multicolumn{2}{c|}{ Group II } \\
\hline The study outcome & \multicolumn{2}{|c|}{ Group I } & Number & $\%$ \\
\hline Mesh salvaged & Number & $\%$ & 5 & $41.7 \%$ \\
Mesh removed & 11 & $91.7 \%$ & 7 & $58.3 \%$ \\
Hernia recurrence & 1 & $8.3 \%$ & 2 & $16.7 \%$ \\
\hline
\end{tabular}

\section{DISCUSSION}

Mesh-related infection after repair of ventral hernia is a dreadful complication. There are many risk factors that eventually result in mesh infection such as diabetes mellitus [DM], chronic kidney disease and steroid therapy.

In our study we had 21 cases suffering from DM, 3 cases with CKD, and one case on steroid therapy for systemic lupus. Classically, the infected prosthesis has to be excised, resulting in losing its main purpose to support the hernia dehiscence. When the mesh is exposed through wound dehiscence, several species of micro-organisms colonize the prosthesis. These microorganisms infiltrated biofilms cover the prosthesis and resulting in antibiotic resistance ${ }^{[11]}$. Therefore, the initial step in the treatment starts with mesh excision to eliminate the source of infection.

VAC by its negative pressure effect expels wound exudate and keeps a balanced moist environment. Wolvos in his study recognized a marked decrease in micro-organisms burden and wound exudates with VAC application ${ }^{[12]}$. Furthermore, NPWT accelerates the formation of granulation tissue, promotes angiogenesis ${ }^{\text {[7- }}$ 9, 12], leading to an acceleration of the healing rate. VAC therapy showed optimistic results in the management of infected/exposed mesh especially in patients with several comorbidities ${ }^{[13]}$.

In our study we had marked reduction in wound size and better granulation tissue formation in VAC group with significant statistical difference $[\mathrm{P}<0.001]$. Berrevoet et $a l$. in their study, reported a similar study that used traditional vacuum-assisted closure therapy and they were able to salvage the prosthesis in sixty cases out of sixty-three ${ }^{[14]}$.
In our study we were able to salvage the prostheisi in 11 cases [91.7\%] in group I compared to only 5 cases [41.7\%] in group II, with significant statistical difference [p-value $<0.001]$. In addition, VAC therapy provides more patient comfort and satisfaction as it avoids repeated daily dressing and annoying wound exudate.

Although it is associated with some movement limitations, it is cost-effective and has a shorter period of therapy and more favorable outcome.

\section{Conclusion}

NPWT/VAC therapy has promising outcomes in the preservation of infected and exposed mesh after hernia repair and thus decreases the possibility of hernia recurrence. Additionally, it was found to be cost-effective in comparison to the conventional dressing method and accelerated wound closure.

Financial and non-financial activities and relationships of interest: None.

\section{REFERENCES}

1. Dabbas N, Adams K, Pearson K, Royle G. Frequency of abdominal wall hernias: is classical teaching out of date? JRSM Short Rep. 2011 Jan 19;2[1]:5. DOI: 10.1258/shorts. 2010.010071.

2. Falagas ME, Kasiakou SK. Mesh-related infections after hernia repair surgery. Clin Microbiol Infect. 2005 Jan;11[1]:3-8. DOI: 10.1111/j.1469-0691.2004.01014.x.

3. Szczerba SR, Dumanian GA. Definitive surgical treatment of infected or exposed ventral hernia mesh. Ann Surg. 2003 Mar;237[3]:437-41. DOI: 10.1097/01. SLA.0000055278.80458.D0. 
4. Delikoukos $\mathrm{S}$, Tzovaras $\mathrm{G}$, Liakou $\mathrm{P}$, Mantzos F, Hatzitheofilou C. Late-onset deep mesh infection after inguinal hernia repair. Hernia. 2007 Feb;11[1]:15-7. DOI: 10.1007/s10029-006-0131-1.

5. Cobb WS, Harris JB, Lokey JS, McGill ES, Klove KL. Incisional herniorrhaphy with intraperitoneal composite mesh: a report of 95 cases. Am Surg. 2003 Sep;69[9]:784-7. PMID: 14509327.

6. Stremitzer S, Bachleitner-Hofmann T, Gradl B, Gruenbeck M, Bachleitner-Hofmann B, Mittlboeck M, Bergmann M. Mesh graft infection following abdominal hernia repair: risk factor evaluation and strategies of mesh graft preservation. A retrospective analysis of 476 operations. World J Surg. 2010 Jul;34[7]:1702-9. DOI: 10.1007/ s00268-010-0543-z.

7. Aufenacker TJ, Koelemay MJ, Gouma DJ, Simons MP. Systematic review and metaanalysis of the effectiveness of antibiotic prophylaxis in prevention of wound infection after mesh repair of abdominal wall hernia. Br J Surg. 2006 Jan;93[1]:510. DOI: 10.1002/bjs. 5186 .

8. Argenta LC, Morykwas MJ. Vacuumassisted closure: a new method for wound control and treatment: clinical experience. Ann Plast Surg. 1997 Jun;38[6]:563-76; discussion 577. PMID: 9188971.

9. Mouës CM, van den Bemd GJ, Heule F, Hovius SE. Comparing conventional gauze therapy to vacuum-assisted closure wound therapy: a prospective randomised trial. J Plast Reconstr Aesthet Surg. 2007;60[6]: 672-81. DOI: 10.1016/j.bjps. 2006.01.041.
10. Morykwas MJ, Simpson J, Punger $\mathrm{K}$, Argenta A, Kremers L, Argenta J. Vacuum-assisted closure: state of basic research and physiologic foundation. Plast Reconstr Surg. 2006 Jun;117[7 Suppl]: 121S-126S. DOI: 10.1097/ 01.prs. 0000225450.12593.12.

11. Cipolla J, Baillie DR, Steinberg SM, Martin ND, Jaik NP, Lukaszczyk JJ, Stawicki SP. Negative pressure wound therapy: Unusual and innovative applications. OPUS. 2008;12: 15-29.

12. Wolvos T. Wound instillation--the next step in negative pressure wound therapy. Lessons learned from initial experiences. Ostomy Wound Manage. 2004 Nov;50[11]:56-66. PMID: 15545698.

13. Jezupovs A, Mihelsons M. The analysis of infection after polypropylene mesh repair of abdominal wall hernia. World J Surg. 2006 Dec;30[12]:2270-8; discussion 227980. DOI: 10.1007/s00268-006-0130-5.

14. Berrevoet F, Vanlander A, Sainz-Barriga M, Rogiers X, Troisi R. Infected large pore meshes may be salvaged by topical negative pressure therapy. Hernia. 2013 Feb;17[1]:67-73. DOI: 10.1007/s10029012-0969-3. 


\section{$1=\sqrt{202(2)}$}

international Journal https://ijma.journals.ekb.eg/ Print ISSN: 2636-4174 Online ISSN: 2682-3780

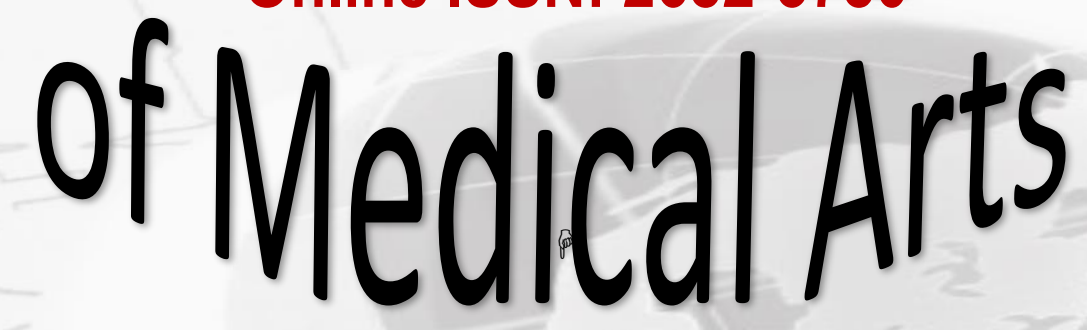

